\title{
Relationship between Child Maltreatment and Alcohol Abuse - Findings from Adverse Childhood Experience Study in Republic of Macedonia
}

\author{
Izabela Filov ${ }^{1 *}$, Marija Raleva ${ }^{2}$, Dimitrinka Jordanova Peshevska ${ }^{3}$, Dinesh Sethi ${ }^{4}$, Gordana Ristevska-Dimitrovska $^{2}$, Kadri $^{2}$ \\ Hazdi Hamza ${ }^{2}$, Ana Poprizova ${ }^{5}$ \\ ${ }^{1}$ Higher Medical School Bitola, University "St. Kliment Ohriski", Bitola, Republic of Macedonia; ${ }^{2}$ University Clinic of \\ Psychiatry, Medical Faculty Skopje, Ss Cyril and Methodius University of Skopje, Skopje, Republic of Macedonia; ${ }^{3}$ World \\ Health Organization, Country Office Skopje, Skopje, Republic of Macedonia; ${ }^{4}$ World Health Organization, Regional Office for \\ Europe, Copenhagen, Denmark; ${ }^{5}$ High School "Orce Nikolov", Skopje, Republic of Macedonia
}

Citation: Filov I, Raleva M, Jordanova Peshevska D, Sethi D, Ristevska-Dimitrovska G, Hazdi Hamza K, Poprizova A. Relationship between Child Maltreatment and Alcohol Abuse - Findings from Adverse Childhood Experience Study in Republic of Macedonia. OA Maced Med Sci. 2014 Jun 15; 2(2):390-394 http://dx.doi.org/10.3889/oamjms.2014.067

Key words: child maltreatment; alcohol abuse healthy risk behaviour; household dysfunction Republic of Macedonia.

"Correspondence: Izabela Filov, MD, PhD. Higher Medical School Bitola, "Vasko Karangelevski bb", 7000 Bitola. Tel: +389 47 Karangelevski bb", 7000 Bitola. Tel: +38947
203 268; Fax: +389 47. E-mail: belafilov@gmail.com

Received: 19-May-2014; Revised: 25-May2014; Accepted: 26-May-2014; Online first: 09-Jun-2014

Copyright: ๑ 2014 Filov et al. This is an open access article distributed under the terms of the Creative Commons Attribution License, which permits unrestricted use, distribution, and reproduction in any medium, provided the original author and source are credited.

Competing Interests: The authors have declared that no competing interests exist.

\section{Abstract}

OBJECTIVES: The aim of the study is to determine the relationship between of the problem of alcohol abuse and child maltreatment.

METHOD: The ACE study was administered by the University Clinic of Psychiatry, Department for Child and Adolescent Psychiatry. The ACE study used a representative sample of students in year four of secondary school (aged 18 and above) and first- and second-year university students. The sample consisted of 664 secondary school students (258 males and 406 females. The university student sample consisted of 613 (343 female and 270 male) students from four universities. The data were obtaining by applying ACE Study Questionnaires.

RESULTS: Individuals who experience psychological abuse are more prone to develop alcoholism. One of the most serious risk factors for abuse and neglect of children was alcoholism, as a form of household dysfunction. Overall, $13.4 \%$ of students lived with someone who misused alcohol. Overall, $10.7 \%$ lived with someone who was alcoholic. The association to each ACE was highest among respondents who grew up with two alcohol-abusing parents compared with persons with no alcohol-abusing parents. The health-risk behaviours of most concern included among the others alcohol use (by $82.2 \%$ of students). Alcohol use is widespread among students and its prevalence rate is almost $28 \%$ by both sexes, and they start drinking at the age of $14-15$.

CONCLUSION: Among the most frequent household dysfunctions was alcohol use by a family member and about $82 \%$ of respondents had ever used alcohol.

\section{Introduction}

Child maltreatment is the abuse and neglect that occurs to children under 18 years of age. It includes all types of physical and/or emotional illtreatment, sexual abuse, neglect, negligence and commercial or other exploitation, which results in in potential harm to the child's health, survival, development or dignity in the context of a relationship of responsibility, trust or power [1].

Child maltreatment causes suffering to children and families and can have long-term consequences. Maltreatment causes stress that is associated with disruption in early brain development. Extreme stress can impair the development of the nervous and immune systems. Consequently, as adults, maltreated children are at increased risk for behavioural, physical and mental health problems such as: perpetrating or being a victim of violence, depression, smoking, obesity, high-risk sexual behaviours, unintended pregnancy, and alcohol and drug misuse. Via these behavioural and mental health consequences, maltreatment can contribute to heart disease, cancer, suicide and sexually transmitted infections.

Several studies have explored the links 
between alcohol abuses as a risk factor associated with child maltreatment.

It is generally known that family environments are usually disrupted by parental alcohol abuse. Strong associations have been found between the availability of alcohol and child abuse and neglect, suggesting that, alongside illicit drugs, alcohol plays a significant role in increasing risks of child maltreatment [2]. Indeed, research has demonstrated that excessive alcohol consumption often plays a part in all of the major forms of child abuse and neglect [3]. Children of alcoholics are at increased risk for various childhood stressors such as abuse, neglect, witnessing domestic violence, or growing up with other forms of household dysfunction [4-7]. It has been estimated that $30 \%$ of child abuse cases involved alcoholic parents, and $60 \%$ of domestic violence cases have occurred when the perpetrator was under the influence of alcohol [8].

In general, families with parental alcohol misuse are characterized by poorer family functioning, perceive their environment to be less cohesive, lack ritual and routines, have lower levels of physical and verbal expressions of positive feelings, warmth and caring, and higher levels of unresolved conflict. There is no clear evidence that maternal alcohol misuse has a greater or lesser impact on children than paternal alcohol misuse. However, children of mothers who misuse alcohol are more likely to be exposed to a variety of risks, for example maternal depression which may result in emotional unavailability to the child [9]. The results from the study conducted in Korea presents the crude and adjusted odds ratios for alcohol abuse. Similar to these findings, is an additional study in 13 runaway and homeless adolescent shelters in the Republic of Korea [10]. Found that adolescents subjected to physical abuse (by anyone in the last year) were more likely to meet problematic criteria for alcohol abuse.

Strong links between parental alcohol abuse and child maltreatment have been found across Australia, with child protection agencies reporting alcohol abuse as one of the top contributors in child protection cases [11-13]. While the multiple issues confronting parents of children in the child protection system confound these figures, experts agree that parental alcohol abuse represents a growing concern for many more Australian children than those currently identified through child protection agencies [14, 15].

The aim of the study is to collect data and determine the magnitude, scope and extent of the problem of adverse childhood experiences, focusing on alcohol abuse via different types of child maltreatment and household dysfunction, among secondary school and university students in Republic of Macedonia and its impact on health risk behaviours such as smoking, alcohol and drug abuse, suicidal behaviour, applying WHO/CDC-recommended methodology. In accordance with expectations, this study will provide data which will fully contribute to bridge the gaps as necessary for applying a public health approach to the problem of child maltreatment, and to further encourage the implementation of evidence-based interventions in the sectors of health, social services and the law on child maltreatment prevention and child protection [16].

The data used in this article is an integral part of the data collected for more comprehensive project "Survey of adverse childhood experiences (ACE) among young people". The study has been conducted 2010. Implementation of the study was enabled with technical and financial support by the World Health Organization in collaboration with the University Clinic of Psychiatry, Medical Faculty in Skopje.

\section{Method}

The study relied upon the efforts of the coordinator, Scientific Steering Committee, Working Group and Field Researchers. The Scientific Steering Committee consisted of a research coordinator, representatives of the Ministry of Education, WHO Country Office Skopje and WHO Regional Office for Europe, Violence and Injury Prevention. The Committee participated in the development of tools for the survey, the sampling strategy and the involvement of schools and universities.

The study was organized in two phases: 1. satisfying legal and ethical criteria for the study and obtaining ethical approval; 2. gathering data required for sampling.

The ACE study used a random selection of a representative sample of students in year four of secondary school (aged 18 and above) and first- and second-year university students. The sample consisted 1227 participants; 664 of them are secondary school students (258 males and 406 females), which represents $2.8 \%$ of the total student population in fourth grade. The secondary schools selected for this study were general and vocational, thus obtaining stratified sampling considering different social strata. The university student sample consisted of 613 (343 female and 270 male) students from four universities, which is $1.9 \%$ of the total student population in the first and second year of studies.

One of the most important scientific developments of the past decade has been proof of the links between child maltreatment, health risk behaviours and certain chronic diseases. A blueprint for any new study investigating these links is provided by the ACE Study Questionnaires. This study examines the prevalence of ACE among secondary school and university students in the Former Yugoslav Republic of Macedonia at national level, applying WHO/CDC-recommended methodology [16].

The ACE Questionnaires were used for this study [17]. These questionnaires, developed by the 
US Centers for Disease Control and Prevention and Kaiser Permanente in 1997, have separate versions for male and female respondents and include the Family Health History and Physical Health Appraisal questionnaires for collecting information on childhood maltreatment, household dysfunction and other sociobehavioural factors [18]. In our study we have used the Family Health History questionnaire without applying the Physical Health Appraisal questionnaire, because the target populations were adolescents and young adults, who are usually a healthy population group in terms of physical health. The Family Health History questionnaire consists of 68 questions examining various types of child maltreatment, childhood adversities rooted in household dysfunctions, and other risk factors. All the questions are introduced with the phrase "While you were growing up, during your first 18 years of life, ..."

For the different types of possible maltreatment, household dysfunction and risk factors, the questions then continue as follows. Health risk behaviour was categorized as:

- smoking

- severe obesity

- physical inactivity

- depression

- $\quad$ suicide attempts

- alcoholism

- drug use

- number of sexual partners

Data input and data analysis were done in SPSS-15 programme using the following methods: descriptive statistical methods (average, standard deviation, percentages, difference test for average and proportion), correlation, chi-square analysis, logistic regression analysis. Statistical significance was set at $p<0.05$ for all analyses. The dataset was edited for inconsistencies. Missing data were not statistically imputed.

This paper analyzes alcohol consumption as a risk factor and its relation with child abuse.

\section{Results}

Alcoholism as a risk factor has been taken into consideration in this study among the others factors (as smoking, severe obesity, physical inactivity, depression, suicide attempts, drug use and number of sexual partners).

A study showed that alcohol use (82.2\%) of students was one of the most concerning behaviours in the sample.

Prevalence of current alcohol use by students shows that almost equal percentages of girls $(28 \%)$ and boys (27\%) used alcohol. Both started drinking early, but boys at 14 and girls at 15 . A significantly higher percentage of boys (11.3\%) had consumed six or more drinks in a single drinking session on three or more occasions during the previous month, in comparison to $3.3 \%$ of girls. Male students reported having a problem with alcohol significantly more often than female students $(8.7 \%$ of males versus $5.1 \%$ of females). Both sexes had similar experience of living with an alcoholic family member (10\% females and 11\%males), (see Table 1).

Table 1: Alcohol use among students by sex and total.

\begin{tabular}{|c|c|c|c|}
\hline Type of risk behaviour & Female & Male & Total \\
\hline \multicolumn{4}{|c|}{ Alcohol use by students } \\
\hline Current alcohol use & $210(28 \%)$ & $142(26.9 \%)$ & $352(27.6 \%)$ \\
\hline Age when start drinking & Av. 15 years & Av. 14 years & \\
\hline $\begin{array}{l}\text { More than six drinks in a } \\
\text { single session } 3 x \text { or } \\
\text { more in last } 30 \text { days }\end{array}$ & $38(3.3 \%)$ & $61(11.3 \%)$ & $99(7.8 \%)$ \\
\hline Problems with alcohol & $38(5.1 \%)$ & $46(8.7 \%)$ & $84(6.6 \%)$ \\
\hline $\begin{array}{l}\text { Living with someone } \\
\text { who was alcoholic }\end{array}$ & 78 (10.4\%) & $58(11 \%)$ & $136(10.7 \%)$ \\
\hline
\end{tabular}

Results presented in the study shows the relationship between adverse childhood experiences such as all types of abuse during childhood and household dysfunction and later manifestation of health-risk behaviours among young people, and adjusted relative odds of health-risk behaviours by type of adverse childhood exposure.

Results showed that alcohol use was one of the most common health-risk behaviour consequences. Of the 1277 respondents, 27.6\% claimed to be current drinkers, and 3.5\% reported having driven a car while drunk (see Table 2). Those who had been physically neglected were twice as likely to drive when drunk. Those who had been physically neglected were twice as likely to drive while drunk. Overall, these results showed that being exposed to negative experiences during childhood is likely to result in a number of risky behaviours in adolescence and young adulthood. The results indicate that alcohol use was one of the most common health-risk behaviour consequences (Table 2).

Table 2: Prevalence and adjusted relative odds of health-risk behaviors (alcohol use and drink driving) by type of adverse childhood exposure.

\begin{tabular}{llllc}
\hline Health-risk behaviors & \multicolumn{2}{c}{ Alcohol use } & \multicolumn{2}{c}{ Drink driving } \\
\hline Prevalence & \multicolumn{2}{c}{$352(27.6 \%)$} & \multicolumn{2}{c}{$45(3.5 \%)$} \\
Emotional abuse & 1.329 & $(0.874-2.022)$ & 0.484 & $(0.114-2.056)$ \\
Physical abuse & 1.206 & $(0.883-1.648)$ & 1.042 & $(0.483-2.248)$ \\
Sexual abuse & 0.657 & $(0.459-0.940)$ & 1.385 & $(0.634-3.949)$ \\
Emotional neglect & 0.922 & $(0.710-2.319)$ & 0.612 & $(0.264-1.414)$ \\
Physical neglect & 0.875 & $(0.642-1.192)$ & 2.007 & $(1.020-5.01)^{\star}$ \\
Substance abuse in family & 0.954 & $(0.662-1.375)$ & 1.275 & $(0.544-2.985)$ \\
Mother treated violently & 1.351 & $(0.871-2.095)$ & 1.160 & $(0.397-3.390)$ \\
Family member in prison & 0.925 & $(0.525-1.629)$ & 1.685 & $(0.492-5.769)$ \\
Mental illness & 1.23 & $(0.678-1.859)$ & & 0 \\
Parental divorce or separation & 1.010 & $(0.526-1.939)$ & 0.776 & $(0.102-5.909)$ \\
\hline
\end{tabular}

The results also demonstrated a relationship between adverse childhood experiences, such as all types of abuse during childhood and alcohol abuse by family member (FM) as a household dysfunction. The most common household dysfunction experienced by those who were abused as children was parental substance abuse (mainly alcohol abuse), for 171 (21$25 \%$ ) of respondents (see Table 3 ). 
Table 3: Relationship between categories of different types of abuse and household dysfunction-substance abuse.

\begin{tabular}{|c|c|c|c|c|c|c|c|c|c|c|c|}
\hline & $\mathrm{N}^{*}$ & $\begin{array}{l}\text { Physical } \\
\text { abuse }\end{array}$ & $\begin{array}{l}\text { Emotional } \\
\text { abuse }\end{array}$ & $\begin{array}{l}\text { Sexual } \\
\text { abuse }\end{array}$ & $\begin{array}{l}\text { Physical } \\
\text { neglect }\end{array}$ & $\begin{array}{c}\text { Emotional } \\
\text { neglect }\end{array}$ & $\begin{array}{l}\text { Parental } \\
\text { divorce }\end{array}$ & $\begin{array}{l}\text { Subst. } \\
\text { abuse }\end{array}$ & $\begin{array}{l}\text { Mental } \\
\text { illness }\end{array}$ & $\begin{array}{l}\text { Mother } \\
\text { treated } \\
\text { violently }\end{array}$ & $\begin{array}{c}\text { Imprisonme } \\
\text { nt }\end{array}$ \\
\hline $\begin{array}{l}\text { First category } \\
\text { of childhood } \\
\text { exposure }\end{array}$ & & \multicolumn{10}{|c|}{ Number and percent (\%) exposed to another category } \\
\hline $\begin{array}{c}\text { Substance } \\
\text { abuse }\end{array}$ & 171 & $\begin{array}{c}60 \\
35.1 \% \\
\end{array}$ & $\begin{array}{c}34 \\
19.9 \% \\
\end{array}$ & $\begin{array}{c}35 \\
20.5 \% \\
\end{array}$ & $\begin{array}{c}54 \\
31.6 \% \\
\end{array}$ & $\begin{array}{c}83 \\
48.5 \% \\
\end{array}$ & $\begin{array}{c}7 \\
4.1 \% \\
\end{array}$ & & $\begin{array}{c}33 \\
19.3 \%\end{array}$ & $29 \quad 17.0 \%$ & $\begin{array}{c}11 \\
6.4 \% \\
\end{array}$ \\
\hline
\end{tabular}

reported current alcohol use [21].

The percentage of students exposed to different forms of household dysfunction, such as alcohol abuse, according to sex showed that there is no statistically significant difference between girls and boys in their adverse childhood experiences, taking into consideration alcohol abuse In our study $78 \%$ of female and $58 \%$ of male have lived with someone with their family environment who had problems with alcohol misuse (see Table 4).

Table 4: Exposure to abuse and household dysfunction (alcohol misuse by family member- FM) by sex and total.

\begin{tabular}{ccrrrrr}
\hline & \multicolumn{2}{c}{ Female } & \multicolumn{2}{c}{ Male } & \multicolumn{2}{c}{ Total } \\
& $\mathrm{N}$ & $\%$ & $\mathrm{~N}$ & $\%$ & $\mathrm{~N}$ & $\%$ \\
\hline Alcohol misuse by FM & 78 & 10.4 & 58 & 11.7 & 136 & 10.7 \\
\hline
\end{tabular}

A study shows another more aspect of the impact of alcohol misuse on children as a method of involvement in sexual activities by perpetrator. The $14 \%$ of female and $20 \%$ of male were given alcohol to be involved in sexual activities (see Table 5).

Table 5: The method of involvement in sexual activities by perpetrator.

\begin{tabular}{lcccc}
\hline & \multicolumn{2}{c}{ Female } & \multicolumn{2}{c}{ Male } \\
\hline $\begin{array}{l}\text { The method of involvement in } \\
\text { sexual activities }\end{array}$ & $\mathrm{N}$ & $\%$ & $\mathrm{~N}$ & $\%$ \\
\hline Given alcohol or drugs & 8 & 14.5 & 22 & 20 \\
\hline
\end{tabular}

\section{Discussion}

Alcohol consumption in the family might be the most common risk factor for domestic violence and child maltreatment. Dube et al. found strong relationships between parental alcohol abuse and each of the 10 ACEs [19]. According to our study the health-risk behaviours of most concern included alcohol use (by $82.2 \%$ of students). Our study shows that alcohol use is widespread among students and its prevalence rate is almost $28 \%$ by both sexes, and they start drinking at the age of 14-15. It is very high percentage when compared with other studies of the same adolescent population. In a recent study of 12 to 18-year-olds receiving routine outpatient medical care in a New England health care network, nearly $15 \%$ had positive results on a substance abuse screening test. [20]. On the other side, results of the prevalence of alcohol use by students in the GSHS $2007 / 2008$ in Republic of Macedonia was $39.4 \%$, which is even higher than in this study, and male students significantly more often than female students
Few studies and numerous investigators have investigated the relationship between childhood victimization and health-risk behaviour consequences manifested by later alcohol use and adult alcohol problems [22, 23]. In our study, of the 1277 respondents, $27.6 \%$ claimed to be current drinkers, and $3.5 \%$ reported having driven a car while drunk.

Those who had been physically neglected were twice as likely to drive while drunk. Overall, these results showed that being exposed to negative experiences during childhood is likely to result in a number of risky behaviours in adolescence and young adulthood. The results indicate that alcohol use was one of the most common health-risk behaviour consequences.

Alcohol use is a serious risk behaviour which can impair adolescents' psychological and physical health and development and influence their relationship with peers, school and family (24).

A strong graded relationship was reported between the number of adverse experiences in childhood (multiple forms of CAN and household dysfunction) and self-reports of health-risk behaviours in adolescence (such as cigarette smoking, alcoholism, drug abuse, obesity, attempted suicide and sexual promiscuity in later life [25].

Among the most frequent household dysfunctions were alcohol and illicit drug use by a family member and violent treatment of the mother. In a study that examined the adverse experiences in childhood in California, USA results show, that $22 \%$ of participants reported having grown up with an alcohol abuser [26]. In our study, this percentage is significantly higher, $78 \%$ of female and $58 \%$ of male have lived with someone with their family environment who had problems with alcohol misuse.

In a developing country like the case of our country, it could be hypothesized that students may have been more exposed to these type of negative experiences, partly or mainly because of poverty and its social effects. However, sociocultural factors can also be cited as important reasons for the development of certain risk behaviours in developing countries [16]. In the Macedonia, for example, peer influence seems to be the strongest factor for adolescents starting and continuing to smoke and drink alcohol. Alcohol consumption is generally a form of socialization that binds relationships among friends. 
The limitations of the study responses were based on self-reports, that imply of likelihood of respondents giving socially desirable answers. The percentage of male respondents who refused to participate in the study was higher than female respondents, mainly due to the length of the questionnaire and lack of insight into their own adverse childhood experiences, as observed by the researchers. A potential weakness of studies with retrospective reporting of childhood experiences is the possibility of recall bias, such as the likelihood that more recent and severe experiences are being reported. Differential recall is also a possibility, depending upon the nature and significance of the events (e.g., sexual abuse compared with emotional neglect).

\section{References}

1. Report on the consultation on child abuse prevention. March 1999.Geneva, World Health Organisation, 1999 (document,WHO/HSL/PVI/99.1).

2. Freisthler B, Needell D, Gruenewald PJ. Is the physical availability of alcohol and drugs related to neighborhood rates of child maltreatment? Child Abuse and Neglect. 2005; 29 1049-60.

3. Laslett A-M, Catalano P, Chikritzhs Y, Dale C, Doran C, Ferris $\mathrm{J}$. et al. The range and magnitude of alcohol's harm to others. Fitzroy, Victoria: AER Centre for Alcohol Policy Research, Turning Point Alcohol and Drug Centre, Eastern Health, 2010.

4. Sher KJ, Gershuny BS, Peterson L, Raskin G.The role of childhood stressors in the intergenerational transmission of alcohol disorders. Journal on the Studies of Alcohol. 1997; 106, 414-27.

5. Sher KJ, Walitzer KS, Wood PK, Brent EE. Characteristics of children of alcoholics: putative risk factors, substance use and abuse and psychopathology. Journal of Abnormal Psychology. 1991;100, 427-48.

6. Windle M, Windle RC, Scheidt DM, Miller GB. Physical and sexual abuse and associated mental disorders among alcoholic inpatients. American Journal of Psychiatry. 1995;152, 1322-28.

7. US Department of Health and Human Services [HSS]. Ninth Special Report to the US Congress on Alcohol and Health. Rockville, MD: Author, 1997.

8. Collins JJ, Messerschmidt PM.Epidemiology of alcohol-related violence. Alcohol Health Research World. 1993;17, 93-100.

9. El-Sheikh M, Flanagan E. Parental problem drinking and children's adjustment: Family conflict and parental depressionas mediators and moderators of risk. Journal of Abnormal Child Psychology. 2001;29(5), 417-32.

10. Park SK, Kim HS, Kim H, Sung KT. Exploration of the prevalence and correlates of substance use among sheltered adolescents in South Korea. Adolescence. 2007; 42(167), 60316.

11. Leek L, Seneque D, Ward K. Parental drug and alcohol use as a contributing factor in applications to the Children's Court for protection orders. Children Australia. 2009; 34, 11-16.

12. NSW Department of Community Services.Annual statistical report 2005-06. Sydney: New South Wales Government. www.community.nsw.gov.au/DOCSWR/_assets/main/docume nts/docs_data/ANNUAL_STATISTICS_ REPORT05-06.PDF. 2007 (Assessed 25 January 2013).
13. Victorian Department of Human Services. An integrated strategy for child protection and placement services. Melbourne: Community Care Division, Department of Human Services, 2002.

14. Dawe S, Frye S, Best D, Moss D, Atkinson J, Evans C, Lynch $M$, Harnett $P$. Drug use in the family: Impacts and implications for children. Canberra, ACT: Australian National Council on Drugs, 2007.

15. Scott D. Think child, think family. Family Matters. 2009;81, 3742.

16. Raleva M, Jordanova Peshevska D, Dinesh Sethi. Survey of adverse childhood experiences among young people in the FYR of Macedonia. Copenhagen. WHO, 2013.

17. Butchart $A$, Kahane T. Preventing child maltreatment: $A$ guide to taking action and generating evidence. Geneva:World Health Organization, 2006.

18. The questionnaire can be downloaded from the web site of the U.S. Centres for Disease Control and Prevention (CDC) at: http//www.cdc.gov/nccdphp/ace/> (accessed 26 June 2011)

19. Dube SR, Anda RF, Felitti VJ, Croft JB, Edwards VJ, Giles WH. Growing up with parental alcohol abuse: exposure to childhood abuse, neglect, and household dysfunction. Child Abuse \& Neglect. 2001;1627-164

20. Substance Abuse and Mental Health Services Administration. Results from the 2009 National Survey on Drug Use and Health: Volume I. Summary of National Findings (Office of Applied Studies, NSDUH Series H-38A, HHS 2010;Publication No. SMA 10-4586Findings). Rockville, MD.

21. Tozija F, Gjorgjev D, Kosevska E, Kendrovski V. 2007/2008 Global school based student health survey results Macedonia. Skopje, National Institute of Public Health, 2009.

22. Miller BA, Downs WR, Testa M. Interrelationships between victimization experiences and women's alcohol use. Journal of Studies on Alcohol. 1993;11(Suppl.):109-1.

23. Wilsnack SC, Vogeltanz ND, Klassen AD, Harris TR. Childhood sexual abuse and women's substance abuse: National survey findings. Journal of Studies on Alcohol. 1997;58(3): 264-271,

24. UNAIDS. Report on the Global HIV/AIDS Epidemic. Geneva; 2004 . http://www.unaids.org/bangkok2004/GAR2004 html/GAR2004 00 en.htm. (Assessed 20 March 2013)

25. Felitti VJ, Anda RF, Nordenberg D, Williamson DF, Spitz AM, Edwards V, Koss MP, Marks JS. Relationship of childhood abuse and household dysfunction to many of the leading causes of death in adults: The Adverse Childhood Experiences (ACE) Study. AJPM. 1998;14:245-58.

26. Schoenborn CA. Exposure to alcoholism in the family: United States, 1988. Advance Data From Vital and Health Statistics, No, 205. National Center for Health Statistics. Hyattsville, MD: US Dept of Health and Human Services.1995;Publication No. (PHS) 95-1880. 